\title{
KNOWLEDGE MANAGEMENT RESEARCH AND END USER WORK ENVIRONMENTS 2010*
}

\author{
By Wilda B. Newman
}

\begin{abstract}
Research in Knowledge Management and collaboration with the Johns Hopkins University, Digital Knowledge Center will allow focus on the future work environment of the University as a whole. The sharing of resources, perspectives, ideas, concepts, and work environments will create a synergy for developing profiles of end users and their Knowledge Management environments. It will look at the published information environment, as well as the overall "information" environment of end users. The research will review how end users currently access and use information and develop future scenarios of end user profiles and how these are structured, from a Knowledge Management perspective.
\end{abstract}

The definition of Knowledge Management as defined by the Gartner Group states that: "Knowledge Management promotes an integrated approach to identifying, capturing, retrieving, sharing, and evaluating an enterprises information assets. These information assets may include databases, documents, policies, procedures, as well as the uncaptured tacit expertise and experience stored in individual's heads" (www.gartner.com). It also includes content management, best illustrated in the "traditional or industrial age library," as well as process flows in automated environments. Knowledge Management is a very broad umbrella and includes by necessity many people of diverse educational and experiential backgrounds. Many of these people are outside the field of Computer Science and are playing an important role in defining and developing the overall understanding of Knowledge Management.

The Milton S. Eisenhower Library at Johns Hopkins University (JHU) has established an R\&D arm that includes the Digital Knowledge Center (DKC) to assist with the transition of the information environment into the new millennium. The transition of this environment includes information that is both published and unpublished, as well as information that is internal and external to the organization.

Paper presented at the 65th IFLA Council and General Conference, Bangkok, Thailand, August 20

- August 28, 1999 - Workshop of the section: Library Theory and Research 
The DKC has two major activities: (1) Evaluation of technology and determining where it is going and the limitations of that technology, and (2) Building collaborative relationships with other areas of the University in general. The DKC focuses are electronic pedagogy, electronic scholarship publishing, and emerging technology. The work proposed will take advantage of these focal points and promote a collaborative approach between the JHU Applied Physics Laboratory and the University as a whole in Knowledge Management.

The use of technology is prevalent throughout our facilities; however, we have yet to leverage that technology in ways that the organization begins to reap more fully the benefits that technology can assist in data, information, and knowledge delivery. This may mean internally produced content or externally produced content and include not only text and graphics but also muti-media, such as streaming video, digitized audio and real time content creation. Knowledge Management also includes procedures and processes that are related and embedded in the functional operations supportive of the infrastructure in the work that occurs as part of all divisions and levels of the University. For example, how will the executive, scientist, researcher, faculty or engineer conduct his or her business, make decisions and manage? How will the administrative, business, or secretarial employees interact in the new environments? And, how will the Program Manager differ in how he or she manages the program environment? In other words, we need to think not just about what we do now, but rather what we do and how we would like to do it in the future. This will require new concepts, tools, and strategies. Basic to this are the building blocks that include knowledge processes, organizational culture, knowledge support, and information technology infrastructure, as noted by Richard N. Fletcher, Principal, Energy Futures Research Associates, Dallas, Texas.

"The future Eisenhower Library will carry forward the digital and network revolutions in the creation, distribution and use of scholarly information but will also integrate a more market-based, customized and entrepreneurial approach to the packaging and delivery of information. The MSEL will become a center for research and development in the application of technology; an aggregator and publisher, and not just a consumer of scholarly information; a campus hub for working with faculty on the integration of technology and electronic resources into teaching and research; a national center for lifelong learning opportunities for information professionals; and a provider of information services to broader academic, research and business communities.

"This vision for the Eisenhower Library predicts a significant moderation in the cost increases for knowledge acquisition as the traditional model of scholarly 
communication is replaced, a redefinition of the MSEL as a virtual resource not limited by time and space and so dependent on buildings for the housing and use of information, and a positioning of the Library as a successful competitor in the information market, and for corporate, foundation and federal investment."

Knowledge Management has many definitions, but is generally acknowledged to be the next "age" or revolution, in businesses and organizations and is seen as a discipline. The concept behind Knowledge Management is applying an environment of management to the most valuable asset of an organization, its knowledge. The research proposed will pursue Knowledge Management as previously defined, that is, as an integrated approach to information assets. These may include databases, documents, policies, procedures, tacit expertise and experience, as well as content management. Collaboration with the Eisenhower Library's Digital Knowledge Center will allow focus on the future work environments of the University as a whole. Further, sharing resources, perspectives, ideas, concepts, and work environments will create a synergy for developing profiles of end users and their Knowledge Management environments. To accomplish this research the following tasks are identified.

\section{Tasks}

- Task - 1 Research the field of Knowledge Management and arrive at a recommended definition for JHU/APL and the University as a whole.

- Task - 2 Interview end users relative to how they work now and how they would like or need to work in the future, with the support of automation, in order to develop end user profiles, current and future.

- Task - 3 Develop VISION 2010 scenarios for end users with the DKC, including the Executive Manager, the Faculty, the Program Manager, the Scientist, the Researcher, the Student, the Administrative Support, and others as perceived.

- Task - 4 Based on the research and work with the Eisenhower Library and the DKC recommend an approach/es for APL and the University for Knowledge Management 2010, including system development and application access.

- Task - 5 This task will be used to assess the research project on Knowledge Management for the Laboratory and the University overall.

An Advisory Group will be formed that includes staff from the University, as well as the APL, including the Director for Research and Exploratory Development. The Advisory Group will be given regular status reports on the work as it progresses and will be asked for feedback on the process. 
The JHU/APL is committed to the field of Knowledge Management with the work of the Research and Technical Development Center and the establishment of an Information Operations Program Development Office, and is one of the Laboratory's strategic plan areas for increased focus in new business development

The DKC at the Eisenhower Library offers a significant opportunity for additional research and collaboration in Knowledge Management, with likely benefits of feeding the efforts of the Laboratory directly, as well as supporting the strategic initiative of APL in its goal to further benefit the government and commercial sectors, while directly supporting the University as a whole. This field is a broad discipline with multiple layers in both depth and breadth, and will require people from many different perspectives for an organization like the Johns Hopkins University to meet the challenge of this next information era.

\section{References}

(1) "Harvard Business Review on Knowledge Management," Harvard Business School Press, 1998, P221.

(2) Davis, Stan, and Meyer, Christopher, "BLUR: The Speed of Change in the Connected Economy" Addison Wesley, 1998, P265.

(3) Naisbitt, John, and Aburdene, Patricia, "Megatrends 2000: Ten New Directions for the 1990s," William Morrow and Co., Inc., 1990, P384.

(4) "Electronic Book '98 Workshop: Turning a New Page in Knowledge Management," 8-9 October 1998, NIST.

(5) "Gartner Group Symposium: The Future of IT. Itxpo97," October, 1997.

(6) Coen, Robert, and Mark C. Hoogenboom, Cap Gemini, "Web-Enabled Applications Programmed on the Net: How to become a Web-Enabled Enterprise," McGraw Hill, 1997, P574.

(7) Hackman, J. Richard, and Oldham, Greg R., "Work Redesign," AddisonWesley Pub. Co., 1980, P330.

Wilda B. Newman

The Johns Hopkins UniversityApplied Physics

Laboratory

Johns Hopkins Road

Laurel, MD 20723, USA

Fax: +19195153628

wilda.newman@jhuapl.edu 